\title{
Cross-Cultural Adaptation and Validation of a Disease Knowledge and Self-Care Questionnaire for a Brazilian Sample of Heart Failure Patients
}

\author{
Eneida Rejane Rabelo ${ }^{1}$ \\ Vanessa Monteiro Mantovani² \\ Graziella Badin Aliti ${ }^{3}$ \\ Fernanda Bandeira Domingues ${ }^{3}$
}

To adapt a questionnaire that assesses knowledge about heart failure (HF) and self-care and to analyze its content validity and reproducibility for use in Brazil. The questionnaire was validated through translation, summary, back-translation, expert committee review, pretest and assessment of psychometric properties. The final version (14 questions) was applied at the university hospital to HF outpatients under multidisciplinary team care. Five questions showed total agreement; seven scored Kappa $>0.4$; one Kappa $=0.4$, and just one presented no agreement. A group of 153 patients within 1-4 years of outpatient follow-

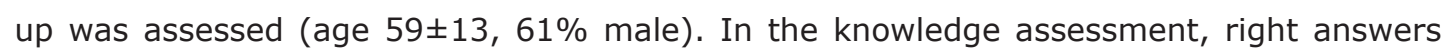
varied from 4 to 14 (average $9.9 \pm 2.1$ ). Results indicate the validity of the questionnaire for use in Brazil.

Descriptors: Heart Failure; Knowledge; Nursing; Validation Studies.

\footnotetext{
${ }^{1}$ RN, Ph.D. in Biological Sciences, Adjunct Professor, Escola de Enfermagem, Universidade Federal do Rio Grande do Sul, Porto Alegre, RS, Brazil. E-mail: eneidarabelo@gmail.com.

2 Undergraduate student in Nursing, Universidade Federal do Rio Grande do Sul, Porto Alegre, RS, Brazil.

${ }^{3}$ RN, M.Sc. in Cardiovascular Sciences, Hospital de Clínicas de Porto Alegre, RS, Brazil. E-mail: Graziela: grazialiti@gmail.com.
} 


\title{
Adaptação transcultural e validação de um questionário de conhecimento da doença e autocuidado, para uma amostra da população brasileira de pacientes com insuficiência cardíaca
}

Esta pesquisa teve como objetivos realizar a adaptação transcultural de um questionário que avalia o conhecimento sobre a insuficiência cardíaca (IC) e o autocuidado e analisar sua validade de conteúdo e a reprodutibilidade para uso no Brasil. O processo de validação constituiu-se de tradução, síntese, retrotradução, revisão por comitê de especialistas, pré-teste e verificação das propriedades psicométricas. A versão final adaptada com 14 questões foi aplicada a pacientes com IC em acompanhamento ambulatorial com a equipe multidisciplinar de um hospital universitário. Quanto aos resultados, cinco questões apresentaram concordância total, sete obtiveram coeficiente Kappa >0,4, uma obteve Kappa 0,4 e apenas em uma questão não houve concordância. Avaliaram-se 153 pacientes, idade de 59 \pm 13 , sendo $64 \%$ sexo masculino; mediana do tempo de acompanhamento no ambulatório de $2(1-4)$ anos. Na avaliação do conhecimento, os acertos variaram de quatro a 14 , média $9,9 \pm 2,1$. Conclui-se pelos resultados, que esse questionário foi validado para uso no Brasil.

Descritores: Insuficiência Cardíaca; Conhecimento; Enfermagem; Estudos de Validação.

\section{Adaptación transcultural y validación de un cuestionario de conocimiento de la enfermedad y autocuidado para una muestra de la población brasileña de pacientes con insuficiencia cardíaca}

\begin{abstract}
Se tuvo por objetivo realizar la adaptación transcultural de un cuestionario que evalúa el conocimiento sobre la insuficiencia cardíaca (IC) y el autocuidado y analizar su validez de contenido y la reproductibilidad para uso en Brasil. Se trata de un proceso de validación constituido de traducción, síntesis, retrotraducción, revisión por comité de expertos, prueba piloto y verificación de las propiedades psicométricas. La versión final adaptada con 14 preguntas fue aplicada a pacientes con IC en acompañamiento en ambulatorio con el equipo multidisciplinar de un hospital universitario. Cinco preguntas presentaron concordancia total; siete obtuvieron coeficiente Kappa > 0,4; una obtuvo Kappa 0,4 y apenas en una pregunta no hubo concordancia. Se evaluaron 153 pacientes, edad de $59 \pm 13 ; 61 \%$ sexo masculino; mediana de tiempo de acompañamiento en el ambulatorio 2 (1-4) años. En la evaluación del conocimiento, los aciertos variaron de cuatro a 14, promedio $9,9 \pm 2,1$. Concluimos que los resultados indicaron que este cuestionario fue validado para ser usado en Brasil.
\end{abstract}

Descriptores: Insuficiencia Cardíaca; Conocimiento; Enfermería, Estudios de Validación.

\section{Introduction}

Treatment of heart failure patients involves pharmacological and non-pharmacological management, with proven effects on lower mortality levels and better quality of life ${ }^{(1)}$. Studies have underlined that patients' understanding about the disease, the benefits of regular medication intake and lifestyle changes decrease decompensation crises and, consequently, reduce hospital readmissions ${ }^{(2-3)}$.
Non-pharmacological management has turned into a cornerstone of HF treatment, in which noncompliance with recommended measures jeopardizes treatment efficiency and effectiveness, compromising patients' clinical stability ${ }^{(1)}$. In the context of the non-pharmacological approach, studies recommend orientations to HF patients about the definition of the disease and its causes, recognition of decompensation 
signs and symptoms, salt and fluid control, physical exercise, weight control, annual vaccination and correct medication intake(4-6).

In this scenario, health literacy has been defined as the ability to obtain, process and understand basic information with a view to correct decision making in health ${ }^{(7)}$. The multidisciplinary team working in outpatient follow-up for HF patients should acknowledge the benefits of health literacy. In addition, they should recognize patients at greatest risk of not understanding the provided information, and mainly know about each patient's learning preferences, besides including strategies to improve patients' knowledge about their disease $^{(8)}$.

In literature, however, few studies have looked at how to measure, through validated questionnaires, whether these patients' education has actually turned into acquired knowledge $\mathrm{e}^{(9-10)}$.

In 2002, an American group developed and validated a heart failure knowledge questionnaire, involving 123 patients $^{(9)}$. This instrument contained 15 questions, addressing general HF and self-care information. The authors of that study showed unsatisfactory knowledge scores among the patients under assessment. Later, a similar study assessed 82 patients, divided between an intervention (follow-up with physician and specialized nurse) and a control group (conventional care with non-specialized team), using a ten-item questionnaire. Patients in the intervention group obtained 7.9 correct answers and in the control group 5.7 correct answers $^{(10)}$.

In view of the importance of assessing patients' knowledge on their disease and treatment and the lack of validated questionnaires in Brazil, this study was designed.

\section{Aim}

To perform the cross-cultural adaptation of a questionnaire that assesses knowledge about heart failure and self-care and to analyze its content validity and reproducibility for use in Brazil.

\section{Methods}

An instrument validation study was carried out at a multidisciplinary HF outpatient clinic of a teaching hospital in Porto Alegre, RS, Brazil.

The original disease knowledge and self-care assessment questionnaire includes questions about: diet (two questions), fluids and weight (two questions), general HF information (two questions), treatment (seven questions), terminal HF (one question) and reasons for re-hospitalization (one question), totaling 15 questions. The original study was published in $2002^{(9)}$. The responsible author authorized the validation for Brazilian Portuguese.

Cross-cultural adaptation was performed according to literature, following the phases suggested by the author: translation, summary, back-translation, expert committee review and pretest ${ }^{(11)}$. To assess the questionnaire's reliability and precision, psychometric property analysis was used(12). Content validity was tested to assess the items' ability to adequately represent the instrument's content dimensions. Content validity is obtained through the expert committee's judgment during the adaptation and translation process, when they equally consider the instrument semantically, idiomatically, culturally and conceptually equivalent ${ }^{(13)}$.

Initial translation to Portuguese involved two distinct translators who mastered both the questionnaire's original language (English) and the language it was translated to (Portuguese). Then, both translators and a third party elaborated the summary, working with the translated and original versions to produce a single instrument. The back-translation involved two other English language teachers with Portuguese as their mother tongue, with a view to assessing whether the contents of the translated version was similar to the original. Afterwards, five cardiology professionals analyzed the translated Portuguese version to assess cultural equivalence (expert committee). The final version in Portuguese, adapted from the English original, was again translated to English and forwarded to the author of the original questionnaire to assess the version. The author approved the adapted instrument with the cultural equivalence changes and did not suggest any further modifications. Next, a pilot study (pretest) was performed which involved 10 patients, with a view to testing the adapted questionnaire. During the pilot study, as much information as possible was obtained about the patients' understanding on the investigated items. The questions were again discussed and some formal changes were made for the sake of a better understanding by the target population. Then, psychometric properties were evaluated, in which the final version was assessed to verify whether the original questionnaire characteristics were maintained. Internal consistency was not assessed due to the lack of a homogenous conception, as questions 
address several themes. Hence, each question group was considered isolated from the others. Reproducibility was assessed to test stability in obtaining the same scores when the questionnaire is applied to the same person at two different times ${ }^{(12)}$. Reproducibility was assessed through the test and retest (Kappa coefficient), which is based on the number of agreeing answers. In this assessment, scores closer to one indicate agreement, while scores closer to zero indicate little or no agreement. Reproducibility assessment involved 51 patients, and the second questionnaire application took place two weeks after the first.

The instrument application included HF patients, of any cause, with left ventricle ejection fraction (LVEF) $\leq 45 \%$, older than 18 years and who agreed to participate in the study. Cardiac arrest patients or who were submitted to coronary artery bypass graft surgery in the past three months were excluded, as well as patients with dementia or cognitive neurological sequelae.

Three questions had to be withdrawn. The first question was related to the quantity of salt in milligrams in a serving of chili sauce; the second to terminal HF, advanced decisions or directives (wills), in which the patient explains what methods (s)he wants to be used to save him/her in case (s)he is in not conditions to speak for him/herself: the third referred to side effects of furosemide. To replace the three questions, one question about physical exercise was added and another about fluid intake. Besides, the number of alternative answers was reduced from five to four. In some questions, mainly related to medicines, the alternative "does not apply" was added, in case the patients do not use the medicine, which makes it difficult to give a correct answer, totaling five alternative answers. The new questionnaire version included questions regarding diet (one question), fluids and weight (three questions), general HF information (two questions), medicines (five questions), physical exercise (one question), measures to improve the $\mathrm{HF}$ (one question) and reasons for re-hospitalization (one question), totaling 14 questions. As for the type of answers the adapted instrument permits, there are 12 multiple-choice questions, one question asks the patients to write in the answer, with one single correct alternative (question 2) and, in question 13), they will only score if they consider all true alternatives correct.

\section{Reproducibility}

Regarding reproducibility, questions $10,11,12,13$ and 14 showed total agreement; questions 1, 2, 3, 4, 5,6 and 8 showed Kappa coefficients > 0.6; question 7 displayed Kappa 0.4 and no agreement was obtained on question 9 only. After this process, the questionnaire was applied to 102 other patients under multidisciplinary outpatient follow-up to test the instrument's validity.

\section{Subjects}

In total, 153 patients were included, with a mean age of $59 \pm 13$ years, $153(64 \%)$ men. The patients' average education was six years, and about $50 \%$ had been under outpatient follow-up for two years. These and other data are displayed in Table 1.

Table 1 Clinical characteristics of 153 participants who answered the adapted version of the heart failure knowledge questionnaire

\begin{tabular}{ll}
\hline \multicolumn{1}{c}{ Characteristics } \\
\hline Age, years & $59 \pm 13^{\star}$ \\
Gender, male & $99(64)^{\dagger}$ \\
Left ventricle ejection fraction (\%) & $34 \pm 11^{*}$ \\
Cause of heart failure & \\
$\quad$ Ischemic & $45(29)^{\dagger}$ \\
$\quad$ Hypertensive & $38(25)^{\dagger}$ \\
$\quad$ Alcoholic & $26(17)^{\dagger}$ \\
Education, years & $6.4 \pm 3.5^{*}$ \\
Comorbidities & \\
$\quad$ Systemic Arterial Hypertension & $86(56)^{\dagger}$ \\
$\quad$ Diabetes Mellitus & $44(29)^{\dagger}$ \\
Retired & $88(58)^{\dagger}$ \\
Time of outpatient follow-up, years. & $2(1-4)^{\ddagger}$ \\
\hline
\end{tabular}

Variables expressed as * means $\pm \mathrm{SD} ;{ }^{+} \mathrm{n}(\%)$ and ${ }^{\ddagger}$ median and percentiles (25-75)

\section{Correct answers: original study and validation study}

Table 2 shows the adapted version of the heart failure knowledge and self-care questionnaire for patients with $\mathrm{HF}$, as well as the 153 patients' respective correct answer rates. Questions 10 and 11, addressing fluid consumption and physical exercise, respectively, were added in the adapted version of the questionnaire to replace the three questions that were removed from the original instrument. 
Table 2 - Correct answers among participants who answered the original version and adapted version of the heart failure knowledge questionnaire

1. Heart failure is a problem in which:
a. there is too much blood in the body.
b. the heart is unable to pump enough blood.
c. the blood vessels in the heart are clogged.
d. does not know.

2. Write in the correct answer. For patients with heart failure, it is important to weigh regularly, each day at the same time, and record the weight. You should visit the doctor or nursing team if you gain more than $\mathrm{Kg}$ in a week:
a. $2,0 \mathrm{~kg}$
b. $6 \mathrm{~kg}$
c. $10 \mathrm{~kg}$

d. does not know

3. Angiotension converting enzyme inhibitors (for example Captopril, Enalapril) are medicines for heart failure patients. These drugs work:

a. to remove extra fluid and salt from the body.

b. to widen the blood vessels in the body.

d. does not know

e. does not apply

4. Angiotension converting enzyme inhibitors (for example Captopril, Enalapril) are medicines that can cause certain signs or symptoms called "side effects". You should tell your doctor or nursing team if you have the following side effects.

a. feeling down or "blue".

b. tremors or "shaking".

c. cough.

d. does not know

e. does not apply

5. People who have heart failure take a pill called digoxin so that:

a. their kidneys will make more urine.

b. the blood vessels in their body will widen.

c. their heart will beat stronger.

d. does not know

e. does not apply

6. When digoxin builds up in the body it can cause signs or symptoms called "side effects". You should tell your doctor or nursing team if you have any of these side effects. In the list below, mark a common side effect of digoxin.

a. erythema (reddish stain) on arms and legs.

b. loss of appetite or bad taste in mouth.

c. sores in mouth

d. does not know

e. does not apply

7. Possible symptoms of heart failure are listed below. Which symptom does not belong on the list?

a. lack of air - shortness of breath.

b. swelling of feet, hands or abdomen.

c. unexpected weight loss.

d. does not know

8. People who have heart failure take diuretics (Lasix - Furosemide) so that:

a. their kidneys will make more urine.

b. their heart will beat more steady.

c. their heart will pump stronger.

d. does not know

9. If you have heart failure and drink alcoholic beverages like beer, wine or "shots", you may have to stop drinking or have:

a. no more than 1 drink per day.

b. no more than 2 drinks per day.

c. no more than 3 drinks per day

d. does not know

e. does not drink alcoholic beverages

10. Which foods below do not contribute to the sum of fluids consumed per day?

a. watermelon

b. bread

c. orange

d. does not know

11. Exercising is good for your health. In your health condition, you:

a. can do any physical exercise, without restrictions.

b. can exercise, if your disease is stable and you do not make too much effort.

c. cannot exercise in any way.

d. does not know 
Table 2 - continuation

Original study

Questionnaire items

12. Because sodium (salt) causes fluid to build up in the body, persons with heart failure need to eat less sodium (salt). Mark the food on the list below that is lowest in salt.

a. canned or powder soup.

b. canned vegetables (for example: corn, peas, gherkins, carrots).

c. fresh fruits and vegetables.

d. does not know

13. Eating less salt is a way to help your heart pump better. What else can you do to improve your heart

failure? (Mark all the alternatives you believe are correct).

a. lose weight if you are overweight.

b. do not smoke.

$--$

c. get a flu and pneumonia shot.

d. does not know

14. Persons with heart failure can feel better by following the plan of care recommended by the doctor or nursing team. Sticking with the plan is the best way to keep out of the hospital. Reasons why some people get symptoms of heart failure and have to go back into the hospital are: (Mark the correct alternative.)

\section{Questionnaire application}

The number of correct answers ranged between four and 14. One patient scored the maximum, correctly answering all questions. The mean number of correct answers was $9.8 \pm 2.1$, with instrument scores varying between zero and 14. Fifty-three percent of patients gave between 10 and 12 correct answers.

\section{Discussion}

In this study, the goal was to cross-culturally adapt a heart failure knowledge and self-care assessment questionnaire and to analyze its content validity and reproducibility for use in Brazil.

Regarding the adaptations, three questions were withdrawn due to their lack of cultural equivalence. To give an example, in the original instrument, one question was related to how many milligrams of salt the patient consumed in a serving of chili sauce. Chili sauce is not common in the Brazilian population, which is why this question was excluded. The second removed question was related to terminal HF, advanced decisions or directives (wills), in which the patient explains what methods (s)he wants to be used to save him/her in case (s)he is in not conditions to speak for him/herself. We decided to withdraw this question as, until date, we experienced no similar situations in our practice.

The last removed question referred to side effects of furosemide. At this outpatient clinic and in our experience, patients do not report such effects. Instead of these questions, one question on physical exercise was added and another on fluid intake.
The number of alternative answers to each question was reduced from five to four, as patients experienced difficulties to remember five answer options per question. As a fourth alternative, the option "does not know" was added. In questions about medicines, the alternative "does not apply" was also added, in case of patients who did not take the respective medicine. In question 9, regarding alcoholic beverage intake, the alternative "does not drink alcoholic beverages was added", as all patients answered that they did not drink on the pretest.

Reproducibility, assessed in 51 patients, showed to be adequate, despite a Kappa coefficient of 0.4 on question 7 and no agreement on question 9. On question 7 , related to HF symptoms, patients were asked to choose the wrong alternative, answering what symptom does not belong to the disease. This opposite approach could hamper the patients' understanding. In comparison with the original study, in which the mean education was 11 years $^{(9)}$, the mean duration of education in this study was six years. Studies have already demonstrated that low education level is associated with bad understanding of written or spoken information, a condition that can jeopardize the accomplishment of health care ${ }^{(14)}$.

In studies involving different samples, aimed at validation HF knowledge assessment questionnaires, Cronbach's alpha amounted to 0.61 and 0.74, respectively ${ }^{(9-10)}$. In knowledge assessment research among nurses active in care delivery to HF patients, regarding the disease and patient orientation topics, results were similar in the group that assessed internal consistency $^{(15)}$ as well as in the group that did not use this method ${ }^{(16)}$. 
The mean number of correct answers was 9.8 2.1 . The minimum number of correct answers was four and one patient got all 14 questions right. In the original study, the mean number of correct answers was 5.83 $2.50^{(9)}$. A similar European study tested and validated a 10-item questionnaire about knowledge on HF self-management, involving 82 patients under outpatient follow-up. In that study, the groups were divided in intervention (education with a physician and nurse specialized in $\mathrm{HF}$ ) and control (conventional care with non-specialized team). The patient received one point for each correct answer. The authors demonstrated that patients from the intervention group scored 7.9, against 5.7 for control group patients ${ }^{(10)}$. These results confirm that patients followed by a specialized team perform better regarding $\mathrm{HF}$ knowledge and self-care.

In another American study that attempted to identify treatment compliance and knowledge levels in $113 \mathrm{HF}$ patients showed that $37 \%$ of patients affirmed they had little or no knowledge about the disease, $49 \%$ affirmed average knowledge and only $14 \%$ a lot of knowledge $\mathrm{e}^{(17)}$. In the present study, in questions addressing general HF information, $74 \%$ of patients managed to correctly define $\mathrm{HF}$, while $77 \%$ could distinguish HF symptoms. Little more than half of the patients, however, could answer the question about weight gain, demonstrating that a large part still does not know about the relation between weight gain and worsening of HF. These data are in line with data from the American study, in which approximately $40 \%$ of patient did not know about the importance of daily weighing and $27 \%$ of patients affirmed weighing twice per month at most ${ }^{(17)}$.

Regarding fluid and salt intake, $38 \%$ affirmed they believe that they should drink a lot of fluid per day and one in every five patients mentioned not knowing about daily salt restrictions. In our results, questions related to fluid and salt intake showed very high levels of correct answers, ranging between $88.9 \%$ and $96.1 \%$.

The questions with lower error levels were related to medicines and their side effects (digoxin, angiotensin converting enzyme inhibitor). On these questions, the number of correct answers ranged between $34.6 \%$ and $51.5 \%$. These data are in line with data found in the American study, in which only $31 \%$ of patients correctly answered questions about medicines ${ }^{(9)}$. On the other questions, related to self-care, reasons for re-hospitalization, general HF information, the number of correct answers ranged between $60.3 \%$ and $94.9 \%$, results similar to the American study, which identified between $50 \%$ and
$75 \%$ of correct answers on these questions ${ }^{(7)}$.

One method to improve patients' knowledge on HF and self-care is to identify patients' learning forms and needs, essential steps for the development of effective education strategies in treatment.

A recently published study investigated learning methods and needs among HF patients hospitalized due to decompensation, using a two-phase questionnaire: the first related to learning styles the patients use most, and the second related to themes patients consider fundamental to know. On the whole, 55 patients completed the questionnaire. Sixty-four percent mentioned they preferred the multimodal style, $18 \%$ through reading/ writing and $11 \%$ prefer hearing someone talk about the theme. Regarding patients' learning needs, signs and symptoms of HF decompensation were considered the most important, followed by disease prognosis and factors contributing to HF development ${ }^{(18)}$.

\section{Study limitations}

One limitation to this research is the withdrawal of two questions, as we do not usually observe similar situations in our clinical practice. These two questions can be validated in future studies though. The first refers to the side effects of furosemide (stomach pain and vomiting, dizziness and ear pain), and the second to the terminality of HF patients.

\section{Conclusion}

After concluding the cross-cultural adaptation phases, this questionnaire was validated in a group of $\mathrm{HF}$ patients and showed to be an adequate tool for knowledge assessment among Brazilian HF patients. It should also be applied to other HF patient groups in other Brazilian regions though, with a view to confirming and expanding its validity.

\section{References}

1. Bocchi EA, Marcondes-Braga FG, Ayub-Ferreira SM, Rohde LE, Oliveira WA, Almeida DR, et al. Sociedade Brasileira de Cardiologia. III Diretriz Brasileira de Insuficiência Cardíaca Crônica. Arq Bras Cardiol. 2009;92(6 supl.1):1-71.

2. Bochi EA, Cruz F, Guimarães G, Moreira FLP, Issa VS, Ferreira SMA, et al. Long term prospective, randomized, controlled study using repetitive education at sixmonth intervals and monitoring for adherence in heart failure outpatients: The REMADHE trial. Circ Heart Fail. 2008; $1: 115-24$. 
3. Jovicic A, Holroyd-Leduc JM, Straus SE. Effects of selfmanagement intervention on health outcomes of patients with heart failure: a systematic review of randomized controlled trials. BMC Cardiovasc Disord. 2006;6:43.

4. Grady KL, Dracup K, Kennedy G, Moser DK, Piano M, Stevenson LW, et al. Team management of patients with heart failure: a statement for health care professionals form the cardiovascular nursing council of American Heart Association. Circulation. 2000;102:2443-56.

5. Rabelo ER, Aliti GB, Domingues FB, Ruschel KB, Brun $A O$. O que ensinar aos pacientes com insuficiência cardíaca e por quê? O papel dos enfermeiros em clínicas de insuficiência cardíaca. Rev. Latino-Am. Enfermagem. 2007;15(1)165-70.

6. Krumholz HM, Amadruta J, Smith GL, Mattera JA, Roumanis SA, Radford $M J$, et al. Randomized trial of an education and support intervention to prevent readmission of patients with heart failure. J Am Coll Cardiol. 2002;39:83-9.

7. Wallace L. Patients' Health Literacy Skills: The Missing Demographic Variable in Primary Care Research. Ann Fam Med. 2006;4:85-6.

8. Evangelista LS, Rasmusson KD, Laramee AS, Barr J, Ammon SE, Dunbar S, et al. Health Literacy and the Patient with Heart Failure-Implications for Patient Care and Research: A Consensus Statement of the Heart Failure Society of America. J Card Fail. 2010;16(1):9-16. 9. Artinian N, Magnan M, Christian W, Lange M. What do patients know about their heart failure? App Nurs Res. 2002;15(4):200-8.

10. Lainscak M, Keber I. Validation of assessment patient knowledge questionnaire for heart failure patients. Eur J Cardiol Nurs. 2005;4:269-72.

11. Beaton DE, Bombardier C, Guillemin F, Ferraz MB. Recommendations for the Cross-Cultural Adaptation of the DASH \& QuickDASH Outcome Measures. Institute for Work \& Health;2007.

12. Waltz CF, Strickland OL, Lenz ER. Measurement in nursing research. 2 ed. Philadelphia: Davis Company, 2005.

13. Fayers PM, Machin D. Scores an Measurements: Validity, Reliability and Sensitivity. Quality of life. Assessment, Analisis and Interpretation. Chichester, England: John Wiley \& Sons; 2007.

14. Berkman ND, DeWalt DA, Pignone MP, Sheridan SL, Lohr KN, Lux L, et al. Literacy and Health Outcomes. AHRQ Evidence Rep. 2004;04-E007-2.

15. Albert NM, Collier S, Sumodi V, Wilkinson S, Hammel JP, Vopat L, et al. Nurses' knowledge of heart failure education principles. Heart Lung. 2002;31:102-12.
16. Washburn SC, Hornberger CA, Klutman A, Skonner L. Nurses' knowledge of heart failure education topics as reported in a small Midwestern community hospital. J Cardiovasc Nurs. 2005;20:215-20.

17. Ni H, Nauman D, Burgess D, Wise K, Crispell K, Hershberger RE. Factors influencing knowledge of and adherence to self-care among patients with heart failure. Arch Intern Med. 1999;159:1613-9.

18. Boyde M, Tuckett A, Peters R, Thompson DR, Turner $C$, Stewart S. Learning style and learning needs of heart failure patients (The Need2Know-HF patient study). Eur J Cardiovasc Nurs. 2009; 8:316-22. 